\title{
sensors
}

ISSN 1424-8220

(C) 2005 by MDPI

http://www.mdpi.net/sensors

\section{Fabrication of Polypyrrole Nanowire and Nanotube Arrays}

\author{
Fa-Liang Cheng*, Ming-Liang Zhang and Hong Wang \\ Dongguan University of Technology, Dongguan 523106, P. R. China \\ * Corresponding author. E-mail: chengfl@dgut.edu.cn
}

Received: 25 June 2004 / Accepted: 5 November 2005 / Published: 15 April 2005

\begin{abstract}
Large area highly uniform and ordered polypyrrole nanowire and nanotube arrays were fabricated by chemical oxidation polymerization with the help of a porous anodic aluminium oxide (AAO) template. Under $0.2 \mathrm{moL} / \mathrm{L}$ pyrrole $\left(\mathrm{H}_{2} \mathrm{O}\right)$ and $0.2 \mathrm{moL} / \mathrm{L}$ $\mathrm{FeCl}_{3}\left(\mathrm{H}_{2} \mathrm{O}\right)$ pattern, polypyrrole nanowire arrays were obtained after 2.0 hours polymerization reaction in a two-compartment reaction cell. When the reaction was stopped after 15 minutes, polypyrrole nanotube arrays have been formed. The diameter, length and density of compositive nanowires and nanotubes could be controlled by parameters of AAO template.
\end{abstract}

Keywords: polypyrrole, nanowire arrays, AAO template, chemical oxidation polymerization.

\section{Introduction}

It is an unquestionable fact that nanomaterials possessed several unique properties superior to their bulky counterparts [1]. Many fabrication methods have been developed, but difficulty and challenge are still exist presently in preparing large area highly ordered nanoarray materials, which would be directly utilized in many devices. Among available approaches, template-based synthesis was well suited for producing arrays with uniform diameters and high aspect ratio wires [2]. Porous anodic aluminium oxide (AAO) templates especially attracted extensive interest because of its desirable characteristics, including highly ordered porous distribution, uniform and tunable pore diameters over a wide rang ( $7-300 \mathrm{~nm}$ ) and lengths (to $>100 \mu \mathrm{m}$ ), good mechanical and thermal stability and welldeveloped preparation methods [3]. Polypyrrole and other conductive polymers stimulated great interest on the basis of their importance in basic scientific research and potential technology applications. Meanwhile, conductive polymer nanomaterials were also extensively studied [4]. 
However, to our knowledge, polypyrrole nanowires or nanotube arrays were less reported than films [5]. Due to the excellent biologic compatibility, catalysis, stability and conductivity, polypyrrole was considered fabricating nanowire and nanotube arrays for using biosensors. Herein, we report a simple chemical oxidation polymerization approach to prepare polypyrrole nanowire and nanotube arrays under room temperature.

\section{Experimental}

All the common chemicals were of analytical grade and were commercially available. The water used in all experiments is twice distilled with a quartz heating tube. A model HITACHI S-5200 scanning electron microscope (SEM) was used for morphology analysis. All experiments were carried out under room temperature (about $20^{\circ} \mathrm{C}$ ).

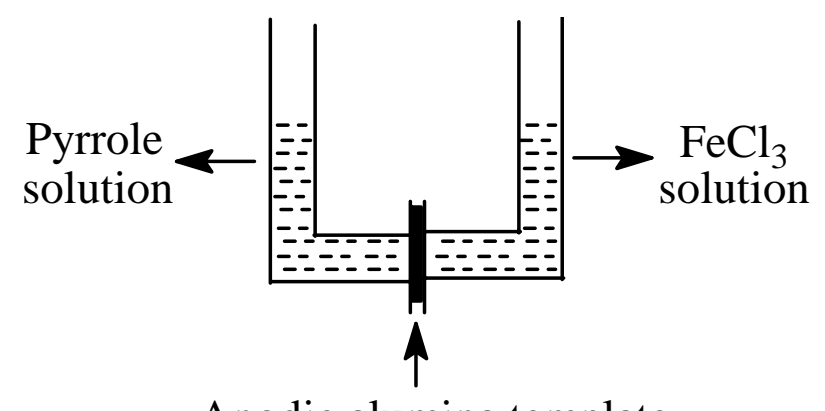

Anodic alumina template

Figure 1. The drawing of reaction equipment.

The experimental equipment and AAO templates were both prepared in our laboratory. The concise drawing of the experimental equipment was shown in Fig. 1. The template was clamped in a twocompartment U-shaped cell. The pyrrole and oxide reagent solutions were carefully added to two cells with the same speed, respectively. The polymerization reaction was carried out under room temperature. The two side solutions diffused to each other through the nanochannels of the AAO template. The balanceable diffusion could be controlled by adjusting the solution height in two Ushaped tubes.

\section{Results and Discussion}

The AAO templates were fabricated by a two-step anodizing approach in $1.0 \mathrm{moL} / \mathrm{L}$ sulfuric acid electrolyte with $20 \mathrm{~V}$ steady potential at $0 \sim 5^{\circ} \mathrm{C}$. The preparing of templates was described in detailed elsewhere [6]. The AAO template possessed closely monodisperse packed hexagonal cylindrical nanochannels with an average porous diameter of $35 \mathrm{~nm}$, a channel length at about $30 \sim 50 \mu \mathrm{m}$ and a porous density of about at $4.8 \times 10^{10}$ pores $\mathrm{cm}^{-2}$. The representative scanning electron microscope photograph of our template was shown in Figure 2.

In the chemical oxidation polymerization reaction, ammonium persulfate $\left(\left(\mathrm{NH}_{4}\right)_{2} \mathrm{~S}_{2} \mathrm{O}_{8}\right)$ and ferric chloride $\left(\mathrm{FeCl}_{3}\right)$ were used as oxidants. $0.2 \mathrm{moL} / \mathrm{L}$ oxidant aqueous solution was placed in the right side compartment. Considering of controlling diffusion speed of the two reactants by changing the 
solvent compatible extent between the two sides of template, pyrrole was dissolved in carbon tetrachloride $\left(\mathrm{CCl}_{4}\right)$, diethyl ether $\left(\mathrm{C}_{2} \mathrm{H}_{5} \mathrm{OC}_{2} \mathrm{H}_{5}\right)$, n-butanol $\left(\mathrm{C}_{4} \mathrm{H}_{9} \mathrm{OH}\right)$, methanol $\left(\mathrm{CH}_{3} \mathrm{OH}\right)$ and water $\left(\mathrm{H}_{2} \mathrm{O}\right)$, respectively. $0.2 \mathrm{moL} / \mathrm{L}$ different pyrrole solution was added to the left side compartment, respectively. Numerous experimental results indicated that under $\mathrm{CCl}_{4} / \mathrm{H}_{2} \mathrm{O}$ and $\mathrm{C}_{2} \mathrm{H}_{5} \mathrm{OC}_{2} \mathrm{H}_{5} / \mathrm{H}_{2} \mathrm{O}$ patterns, polymerization reactions were very slow; furthermore, no nanowires were obtained and usually produced some films on the templates surface. Under $\mathrm{C}_{4} \mathrm{H}_{9} \mathrm{OH} / \mathrm{H}_{2} \mathrm{O}$ and $\mathrm{CH}_{3} \mathrm{OH} / \mathrm{H}_{2} \mathrm{O}$ patterns, although polymerization reaction rate were relatively appropriate, the synthetic nanowire arrays were not good. Lots of them were broken and some segments were dispersed during removing the templates. The possible reasons are that many diminutive air bubbles would be produced during the interdiffusion process with releasing of dissolving heat, which made polymerization reaction uneven. Consequently, the polypyrrole nanowires were loose and easily broken. The last polymerization reactions were carried out rapidly and effectively under $\mathrm{H}_{2} \mathrm{O} / \mathrm{H}_{2} \mathrm{O}$ homogeneous pattern. Compared with $\left(\mathrm{NH}_{4}\right)_{2} \mathrm{~S}_{2} \mathrm{O}_{8}$, $\mathrm{FeCl}_{3}$ used as oxidant made polymerization reaction more effective and the obtained polypyrrole nanowires were better. It is obvious that the $\mathrm{Fe}^{3+}$ ion is smaller than the $\mathrm{S}_{2} \mathrm{O}_{8}{ }^{2-}$ ion. In addition, the anodic alumina template used in our experiments only possessed $30 \mathrm{~nm}$ porous diameters. So the $\mathrm{Fe}^{3+}$ ion could move more freely in the template nanochannels than the $\mathrm{S}_{2} \mathrm{O}_{8}{ }^{2-}$ ion.

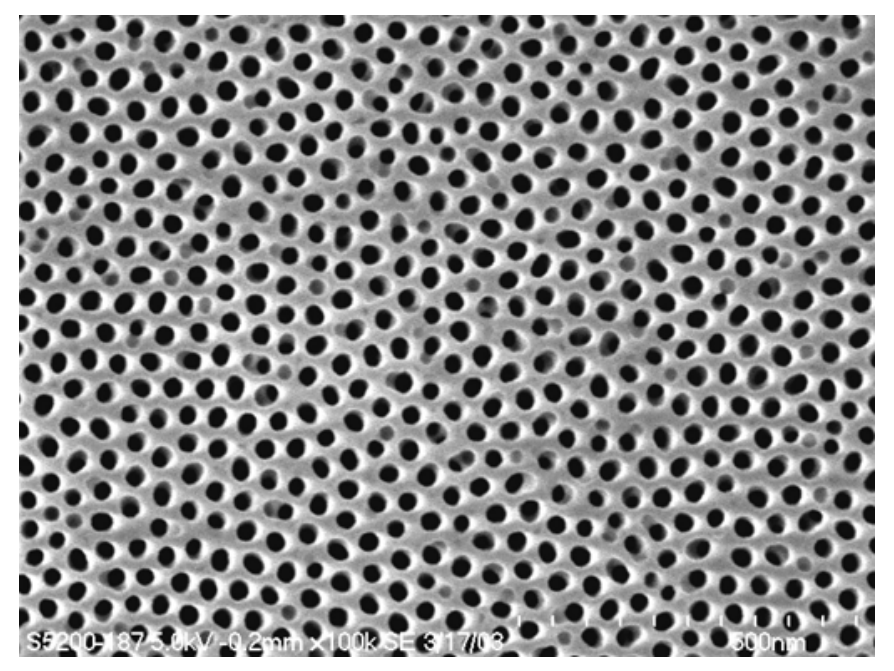

Figure 2. The SEM photograph of AAO template.

The influence of reactants concentrations on the polymerization reaction was investigated. The concentration ratio of pyrrole and $\mathrm{FeCl}_{3}$ was kept at 1:1. Polypyrrole nanowire arrays were fabricated under the reactants concentration at $1.0,0.8,0.6,0.4,0.2,0.05$ and $0.01 \mathrm{moL} / \mathrm{L}$, respectively. The results show that at high concentrations, the polymerization reactions were fast and there were thick polypyrrole layers on the two surfaces of the templates. The nanowires were not uniform, loose and broken. The possible reason is that the polymerization reaction is too fast and the formed polypyrrole has no time to assemble. Moreover, two polypyrrole layers on the surfaces of template blocked the diffusion of reactants in the nanochannels. On the other side, when the reactants concentrations were lower than $0.01 \mathrm{moL} / \mathrm{L}$, it was difficult to form polypyrrole nanowire arrays. Thinking of efficiency and quality, $0.2 \mathrm{moL} / \mathrm{L}$ was selected as the optimal concentration. Under $0.2 \mathrm{moL} / \mathrm{L}$ pyrrole $\left(\mathrm{H}_{2} \mathrm{O}\right) / 0.2 \mathrm{moL} / \mathrm{L} \mathrm{FeCl}_{3}\left(\mathrm{H}_{2} \mathrm{O}\right)$ pattern, the reaction time was further optimized. Many experimental results revealed that the polypyrrole nanowire arrays were basically formed after 2.0 hours. 
Under optimal experimental conditions, after the end of the reaction, the template was taken out and polypyrrole on the template surfaces was carefully scraped off. The template was removed with $5 \%$ $\mathrm{H}_{3} \mathrm{PO}_{4}$ aqueous solution. An exemplary SEM photograph was shown in Figure 3. From that, although some portions were collapsed, it is clear that the nanowire array was highly ordered and uniform on a large area. The inset has indicated the amplificatory polypyrrole nanowires with $38 \mathrm{~nm}$ uniform diameters. Considering a little swell of the nanowires after removing the template, it agreed well with the porous diameters of the used template.

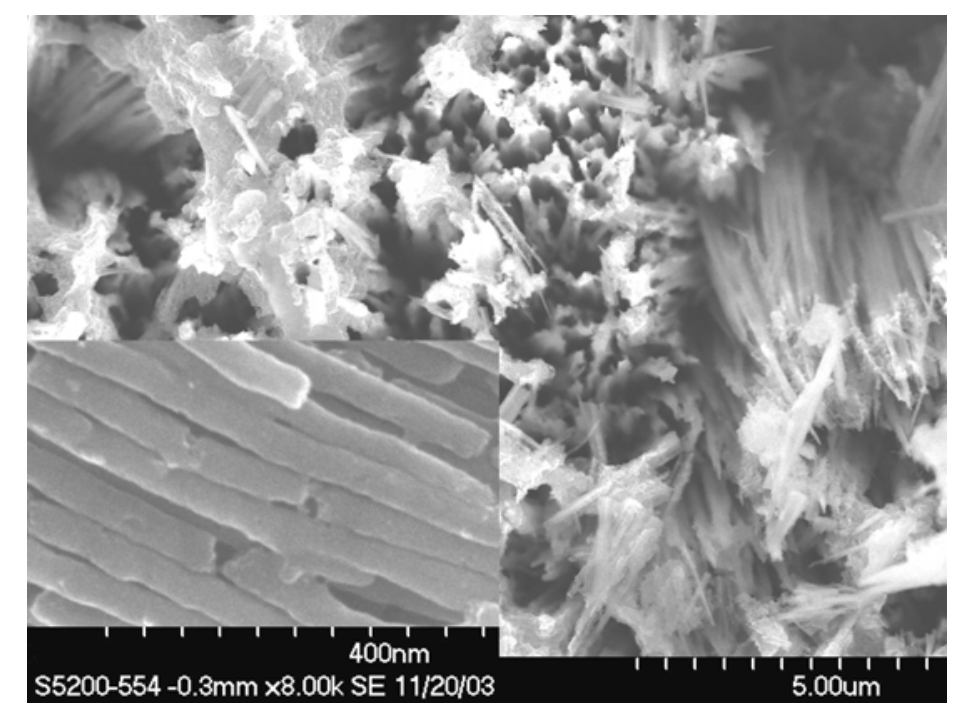

Figure 3. Polypyrrole nanowire array (SEM photograph).

In order to investigate the polymerization process, the polymerization reaction was ceased after 15 minutes. In this experiment, another kind of AAO template with about $60 \mathrm{~nm}$ porous diameter was utilized. The result was shown in Figure 4. For clarity of SEM, the template was not removed completely.

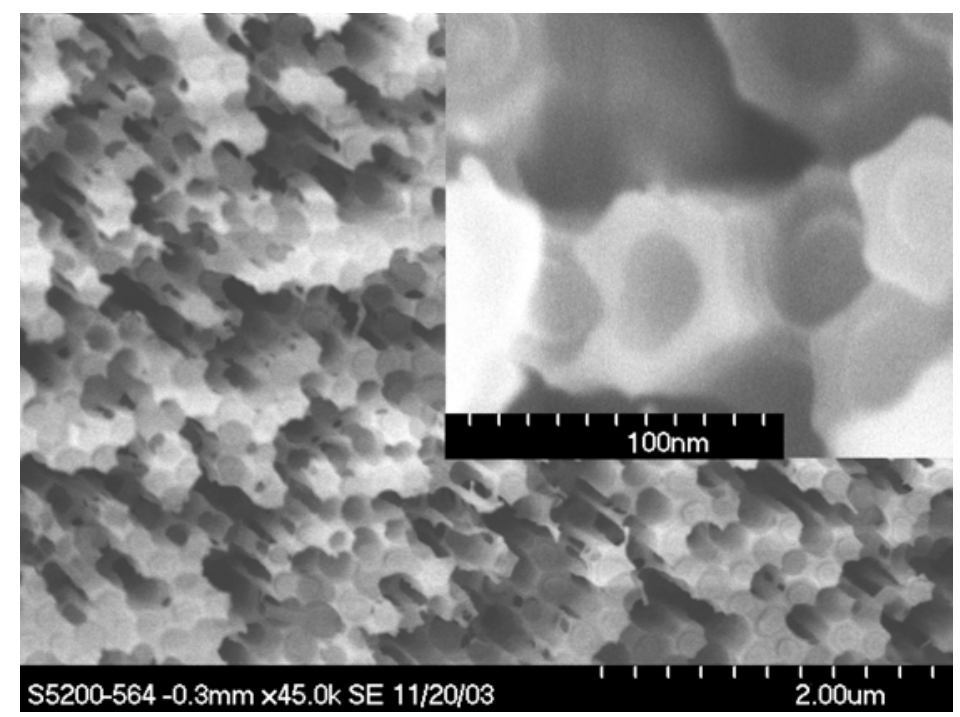

Figure 4. SEM photograph of polypyrrole nanotube array. 
One can see that a large-scale uniform polypyrrole nanotube array has been formed. The inset indicated that the polypyrrole nanotubes were hexagonal prism and possessed about $60 \mathrm{~nm}$ outer diameters and $10 \mathrm{~nm}$ wall thickness. This result helped us to confirm that polypyrrole nanowires are formed from outer diameter to inner diameter, which agrees to the previous research report [7]. This experiment also made us believe that we could obtain many different parameters for polypyrrole nanotube arrays by controlling the polymerization reaction times and conditions. Further systematic works are in progress.

In conclusion, large-scale highly uniform polypyrrole nanowire and nanotube arrays have been fabricated under room temperature with an AAO template aid. The polymerization reaction conditions were optimized. The experimental results revealed that polypyrrole was formed from wall to the center of nanochannels. If the different parameters for AAO templates were used, corresponding polypyrrole nanowire and nanotube arrays could be obtained.

\section{Acknowledgements}

This work was supported by the National Natural Science Foundation of China (20375008), the Natural Science Foundation of Guangdong Province (32167), Technologies R\&D Programs of Guangdong Province (C31902) and the Natural Science Research Programs of High School (Z03091).

\section{References}

1 Jin, R.; Cao, Y.; Mirkin, C. A.; Kelly, K. L.; Schatz, G. C.; Zheng, J. G. Photo Induced Conversion of Silver Nanospheres to Nanoprisms. Science, 2001, 294, 1901-1903.

2 (a) Martin, C. R. Nanomaterials: a membrane-based synthetic approach. Science, 1994, 266, 1961-1966; (b) Martin, C. R. Membrane-Based Synthesis of Nanomaterials. Chem. Mater. 1996, 8, 1739.

3 (a) Masuda, H.; Hasegwa, F.; Ono, S. Self-ordering of cell arrangement of anodic porous alumina formed in sulfuric acid solution. J. Electrochem. Soc. 1997, 144, L127-L130; (b) Jessensky, O.; Müller, F.; Gösele, U. Self-organized formation of hexagonal pore arrays in anodic alumina. $J$. Appl. Phys. 1998, 72, 1173-1175.

4 (a) Choi, S. J.; Park, S. M. Electrochemical Growth of Nanosized Conducting Polymer Wires on Gold Using Molecular Templates. Adv. Mater. 2000, 12, 1547; (b) Fu, M. X.; Zhu, Y. F.; Tan, R. Q.; Shi, G. Q. Aligned Polythiophene Micro- and Nanotubules. Adv. Mater. 2001, 13, 1874-1877.

5 Demoustier-Champagne, S.; Ferain, E.; Jérôme, C.; R. Jérôme, R.; Legras, R. Electrochemically synthesized polypyrrole nanotubules: effects of different experimental conditions, Eur. Polym. J. 1998, 34, 1767-1774.

6 Cheng, F. L.; Jing, B. K.; Wang, H.; Wu, J.; Zhang, M. L. Study on Preparation of highly ordered nanochannel array aluminum oxide template. Asian J. Chem. 2004, 16, in press

7 Duchet, J.; Legras, R.; Demoustier-Champagne, S. Chemical synthesis of polypyrrole: Structureproperties relationship. Synth. Met. 1998, 98, 113-122.

(C) 2005 by MDPI (http://www.mdpi.net). Reproduction is permitted for noncommercial purposes. 